\title{
EMOÇÃO NA TORCIDA DE FUTEBOL: UMA PAIXÃO PERIGOSA
}

Jairo Antonio Paixão, Universidade de Trás-os-Montes e Alto D'Ouro - UTAD, Portugal Marizabel Kowaslki, Universidade Federal de Viçosa - UFV, Viçosa, Minas Gerais, Brasil

\section{Resumo}

O presente estudo tem como objetivo discutir o fenômeno futebol como uma paixão perigosa, aquela que induz indivíduos e grupos ao risco de morte. A literatura revista aponta para o fato que a emoção quando levada ao extremo, pode ser violenta na movimentação da massa humana, na excitação da vitória e transposição da derrota. Ainda que os estádios de futebol se configurem como espaços destinados a excessos e euforias coletivas, propõe-se a efetivação da regulamentação em que se estrutura o futebol nos estádios, contribuindo assim para se evitar o descontrole das paixões e emoções pelos torcedores e por sua vez, a banalização de atos violentos e mortes.

Palavras-Chave: Futebol; Violência; Emoção.

\section{EMOTION IN SOCCER SPECTATORS: A DANGEROUS PASSION}

\begin{abstract}
This study aims to discuss the phenomenon of soccer as a dangerous passion, one that leads individuals and groups at risk of death. The literature reviewed points to the fact that emotion when taken to extremes may be violent in handling the mass of humanity, in the thrill of victory and defeat transposition. While the stadiums are configured as spaces for collective euphoria and excesses, it is proposed the effectiveness of the regulatory structure in which the football stadiums. Such action would be able to bring significant contributions to avoid the uncontrolled passions and emotions of the fans in the stadiums and turn the trivialization of violence and deaths.
\end{abstract}

Key-Words: Soccer; Violence; Emotion. 


\section{INTRODUÇÃO}

O comportamento agressivo e violento de um ser humano para com o outro não é um fenômeno novo. Segundo Cagigal ${ }^{1}$ trata-se de uma ação que se apresenta de forma indiscriminada e generalizada em quase todas as sociedades, manifestando-se de forma oral ou simbólica e, principalmente, por meio da agressão física. Murad ${ }^{2}$ acresce que tal prevalência confere às ações agressivas e violentas o status de problema social, digno de atenção mundial. Constantemente, eventos dessa natureza em diferentes proporções como tiroteios em escolas, atentados terroristas como o ocorrido no World Trade Center em 11 de setembro de 2000, deixam sensibilizados sobre o próprio destino humano.

A realidade confirma a falta de controle das emoções nos diversos setores que compõem a vida em sociedade, resultando em eventos violentos, como por exemplo, os que ocorrem constantemente entre torcedores de futebol que freqüentam estádios em todo o mundo. ${ }^{3-7}$

Dunning $^{8,9}$ afirma que, dentre os inúmeros fatores que concorrem para incidência de casos de ações violentas no futebol, encontra-se a popularidade da modalidade esportiva, cuja, composição social de suas multidões advém de escalas populares da sociedade e a maioria dos seus espectadores serem do sexo masculino.

Segundo o autor, a aclamação ao futebol pela massa evidencia a "paixão" pelo time, clube e/ou seleção nacional como justificativa da efusão de sentimentos pelos torcedores com sensações de pertencimento, reputação a ser conservada, emoção, afirmação da masculinidade e prazer provocados pela excitação emocional e devoção aos componentes esportivos. Os conflitos em que tomam parte são percebidos pelos torcedores como situações de luta com sentimentos calorosos, gratificantes e prazerosos.

Parece não haver espaço para o sentimento de culpa e/ou arrependimento dos desfechos de ações, sejam elas de pura explosão de emoção decorrente da comemoração de um gol de seu time ou mesmo agressões físicas, provocações e ofensas proferidas por esses apaixonados no decorrer, ou após o jogo.

Nessa perspectiva, o estudo tem como objetivo analisar o fenômeno esportivo como uma emoção perigosa, aquela que induz indivíduos e grupos ao risco de morte. Considerou-se a hipótese de que a emoção levada ao extremo pode ser violenta na movimentação da massa humana na excitação da vitória e transposição da derrota. 


\section{MÉTODO}

Trabalhando em conformidade com Marconi e Lakatos, ${ }^{10}$ fez-se uso da técnica da pesquisa bibliográfica, utilizando as fontes bibliográficas do tipo de publicação, encontradas em livros, artigos, sites e publicações avulsas.

Organizou-se o estudo em dois momentos. De início, a partir da fundamentação na teoria da emoção $^{11}$ e da paixão, ${ }^{12}$ abordaram-se ações violentas dos torcedores em função de sentimentos decorridos nas partidas de futebol. Por fim, estabeleceram-se relações entre paixão e ira - poder e violência e sua repercussão no comportamento violento de torcedores que frequentam os estádios, ancorados em Arendt ${ }^{13}$, Elias e Dunning ${ }^{14}$.

\section{FUTEBOL E EMOÇÃO}

Há muito que o ser humano tenta entender o que é emoção. Conforme Abbagnano, ${ }^{15}$ na filosofia clássica, Platão a entendia como algo desconcertante que interrompia o exercício pleno da razão. Aristóteles julgava-a como a combinação da vida cognitiva - entendida como atividade superior - com a vida sensual - entendida como atividade inferior. ${ }^{15-16}$

Com o surgimento das teorias psicológicas, no final do século XIX, o conceito de emoção passou a ser revisto, questionando, o que predominara até então a partir da obra de Descartes. ${ }^{17}$ Etimologicamente, o termo "moção" evoca movimento, o prefixo $e$, indica direção ao exterior. ${ }^{18}$

No século XIX, Darwin ${ }^{19}$ trouxe contribuições para a construção do novo entendimento sobre a emoção. Ele sugeria que as expressões emocionais decorrem da forma como o sistema nervoso foi sendo moldado a partir das adaptações pelas quais o homem passou ao longo da história das espécies.

Para Goleman, ${ }^{11}$ a emoção se refere a um ou a vários sentimentos e a seus distintos pensamentos, estados psicológicos e biológicos, e a uma gama de tendências para agir. Ele nos leva a pensar as emoções em termos de famílias, dimensões ou domínios. As principais famílias das emoções são: ira, tristeza, medo, prazer, amor, surpresa, nojo e vergonha. 
Strongman ${ }^{12}$ observa que as paixões primitivas de admiração, amor, ódio, desejo, alegria e tristeza não são básicas, nem têm semelhança animal, mas são indiscutivelmente de natureza humana. O racionalismo cartesiano, segundo o autor reforça esse conceito ao postular que as emoções eram assunto de natureza típica da alma, portanto, exclusivamente humana.

Analisando os aspectos da violência física e simbólica, evidenciaram-se as interfaces com o esporte partindo da perspectiva histórica do desenvolvimento da sociedade. Observa-se que o controle das emoções e da violência dentro e fora da situação de jogo é intenso. Entretanto, as expressões repugnantes da violência simbólica se tornaram comuns envolvendo situações de discussões, ameaças verbais e até mesmo agressões morais. A violência, em torno do e através do esporte, é um objeto de estudo permeado de obscuridades, embora muitos autores o apresentem com explicação histórica correlacionada aos fatos que levam à ação violenta.

Segundo Huizinga, ${ }^{16}$ a inserção dos impulsos agonais no esporte e a necessidade de autoafirmação por via competitiva, continua sendo a dominante rotina da cultura ocidental. $\mathrm{O}$ indivíduo está cada vez mais impregnado disso, quase sempre sem saber, mesmo no momento em que os meios para se satisfazer tornam discutíveis. Quando é demasiado intenso o desequilíbrio entre os meios empregados e o fim para a vitória, a violência surge como último recurso.

O futebol caracteriza-se como um fenômeno eminentemente moderno e urbano, cuja evolução está vinculada às condições históricas que marcaram o fím do século XIX e o início do século XX atingindo diferentes classes sociais contemporâneas. ${ }^{20}$ Visto dessa forma, o futebol faz parte do cenário urbano presente nos espectadores aficionados, simpatizantes e torcedores, podendo ser percebido no andar em bando, na camisa do time, diferenciando-se do todo e construindo para si e para o grupo uma nova forma de sociabilidade identitária. ${ }^{21-22}$

De acordo com Paula ${ }^{22}$ (2005), o futebol nasceu como disputa dual, onde as equipes representavam grupos ou identidades coletivas, nações, localidades geográficas e culturas específicas. Na Grã-Bretanha, séculos XIII e XIV, estavam presentes os pontapés, socos e chutes como maneira socialmente aceita entre os jogadores, bem como, o porte de armas como facas e punhais para acertar antigos conflitos e rixas ou com a intenção de causar ferimentos em seus adversários em campo. ${ }^{20}$ 
A dinâmica do jogo de futebol favorece uma espécie de oposição binária, quando cada jogador se encontra comprometido com uma batalha pessoal com o lado oposto e o seu marcador individual é o seu inimigo. ${ }^{20}$ Logo, o desempenho em campo depende da capacidade de superar o rival emergindo desse conflito velhas questões de etnia, classe e animosidade entre as classes, dominante e dominada.

Nesse contexto, tomadas pela paixão e emoção, as torcidas organizadas ultrapassam os limites possíveis de condutas permitidas pelas normas vigentes socialmente. Emergem as formas arrebatadas de violência e brutalidade como estratégias inconsequientes, que buscam a intimidação dos seus pares que, no momento presente, se configuram como rivais.

Ao longo do tempo, diferentes eventos evidenciaram o lado violento e agressivo do futebol envolvendo praticantes e torcedores, como pode ser verificado em um estudo realizado na década de 1980 por Willians, Dunning e Murphy. ${ }^{23}$

Tabela 1 - Incidentes violentos envolvendo torcedores de times de futebol

\begin{tabular}{ccccc}
\hline País & Ano & Time & Mortos & Feridos \\
\hline Peru & 1964 & Peru x Argentina & $287-328$ & 5000 \\
Turquia & 1964 & Kayseri x Sivas & 44 & 600 \\
Argentina & 1968 & River Plate x Boca Juniors & 74 & 150 \\
Brasil & 1982 & São Luis x Fortaleza & 3 & 25 \\
Colombia & 1982 & Deportivo Cali x Club & 22 & 200 \\
& \multicolumn{1}{c}{ Argentina } & 69 & 100 \\
\hline USSR & 1982 & Moscow Sparta x Haarlem &
\end{tabular}

Willians et al. (1984).

Kowalski ${ }^{24}$ destaca que, nesses momentos, ocorre o fato da concretização da violência no qual o torcedor se sente justificado de que trava um combate em defesa de seu time, pelas cores da bandeira que carrega, exacerbando um tipo de fundamentalismo e fanatismo que caracterizaremos como - emoção perigosa.

Observa-se que esta qualificada alienação faz com que espectadores comuns, ao se postarem como torcedores e ativistas adentrando no estádio, abandonam sua identidade e se transformam em máquinas "urrantes" com sentido único - não mais esportistas - agora aficionados. 
Em decorrência dessa realidade, recorreu-se à Maffesoli ${ }^{25}$ que se utiliza da expressão metafórica tribos urbanas $^{l}$ para designar os grupamentos humanos que buscam, acima de tudo, contestar o individualismo e outras implicações percebidas nas relações sociais estabelecidas na contemporaneidade.

A partir do sentido atribuído pelo autor a expressão tribo urbana, é possível estabelecer uma espécie de analogia entre os integrantes dessas tribos e os torcedores de futebol que freqüentam os estádios. Os torcedores se associam objetivando compartilhar o sentimento de pertencimento, supremacia, emoções e outras sensações proporcionadas pela performance de seu time.

Esse fato os coloca numa situação de busca constante por vivências intensas e sensações presentes nos estádios. A partir dessas afirmações, faz-se oportuno ressaltar o significado de 'errância' considerado por Maffesoli. ${ }^{25}$ Estes torcedores 'errantes' geralmente empreendem uma sucessão de experiências, freqüentemente perigosas e por vezes trágicas, mas que lhes propiciam instantes de emoções fortes, sentimentos arriscados à sua vida e a pessoas que formam as torcidas.

\section{Paixão e ira: poder e violência}

Enquanto fenômeno social é muito difícil conceituar e/ou detectar as causas primeiras da violência. Isso se deve ao fato de a violência assumir variações quanto a sua natureza e formas de manifestação na organização de coletividades. Por vezes, a violência toma forma própria de relação pessoal, política, social e cultural; e por outras; resulta de interações sociais; ou ainda por um componente cultural naturalizado. ${ }^{26}$ A partir de estudos nas diferentes áreas do saber ${ }^{13,26-30}$ levam a crer que a única certeza se apóia na prevalência da violência no âmbito dos diferentes grupamentos humanos.

\footnotetext{
1 A expressão "tribo urbana" foi utilizada pela primeira vez pelo sociólogo francês Michel Maffesoli em seus artigos a partir de 1985. Três anos depois a expressão ganha força com a publicação de Le temps des tribus: le déclin de l'individualisme dans les sociétés postmodernes, do referido autor. O uso da noção era metafórico, para dar conta de formas supostamente novas de associação entre os indivíduos na sociedade pós-moderna: o autor fala em neotribalismo. Seriam essencialmente micro-grupos que, forjados em meio à massificação das relações sociais baseadas no individualismo e marcados pela unissexualização do pensamento, da aparência física, dos usos do corpo e do vestuário, acabariam, mediante sua sociabilidade, por contestar o próprio individualismo vigente no mundo contemporâneo (Frehse, 2006). Essas tribos reforçam um sentimento de pertença, buscam acima de tudo uma nova identidade (Maffesoli, 2006).
} 
A violência pode se manifestar ainda como fator de unicidade, força de ligação de uma sociedade ou grupo. Segundo Arendt, ${ }^{13}$ (p. 50), "o encantamento inebriante da prática da violência que amarra os homens em um todo coeso, pois cada indivíduo forma um elo violento na grande cadeia, torna-se uma parte do grande organismo da violência em expansão".

Analisando os aspectos da violência física e simbólica evidenciam-se as interfaces com o esporte partindo da perspectiva histórica do desenvolvimento da sociedade. ${ }^{14}$

É fato que a violência se encontra presente nos estádios, quando lá se reúnem tribos de torcedores de futebol. É nesse tempo e lugar que as manifestações da violência simbólica se tornaram comum envolvendo situações de discussões, ameaças verbais e, até mesmo, agressões morais entre os jogadores. ${ }^{23}$

Nos estudos sobre as transformações no futebol dos Estados Unidos e Inglaterra, Elias e Dunning $^{14}$ notaram originalmente que os americanos temiam estas brutalidades excessivas, mas, ao mesmo tempo, encontravam prazer nelas, e que, por conseqüência, sentiam uma grande dificuldade em reconhecer o sentido das violências exteriores aos campos esportivos.

Após a intervenção do presidente americano, Roosevelt em 1905, a tática e a técnica desenvolveram e aperfeiçoaram o passe e a velocidade do jogo, conseqüentemente diminuindo os acidentes graves e muitos deles mortais, cuja necessidade foi definir; limitar e submeter para convenções o simbolismo da violência nos esportes. ${ }^{14}$

Segundo Arendt, ${ }^{13}$ a violência ao longo dos tempos é explicada como um meio de ampliar e multiplicar o vigor humano. Os fatos históricos do esporte na antiguidade relatam a atividade física onde a violência era a consumação da vitória e do poder do vencedor sobre o perdedor, ou seja, na desintegração do poder ensejava a violência.

A autora interpõe poder e violência como termos opostos, ou seja, a violência destrói o poder, não o cria. Entretanto a afirmação absoluta de um, não significa a ausência do outro. A apologia à violência repete-se singularmente no livro "Sobre a Violência" o que incitou esta investigação acerca da natureza e causas da violência. A análise de fatos históricos, ações 
políticas, depauperações econômicas e atrocidades ocorridas não justificam a glorificação da violência. ${ }^{13}$ (p. 54).

A violência e glorificação presentes explicam a severa frustração da faculdade de agir no mundo contemporâneo. Os seres sociais agem pelos impulsos e se tornam irracionais manifestando-se de modo violento. A violência é uma atitude irracional, mas é racional no momento em que a reação no curso de um conflito se transforma em ação e, no calor da emoção, reúne varias pessoas num mesmo grupo social. Na multidão, esse ser social não tem nome, identidade, profissão, sexo e não segue as leis, as regras e, acima de tudo, os comportamentos e condutas são negligenciados. A ação do torcedor desprenderá o jogo da excitação - vitória versus derrota, emoção versus ira. No calor da partida com o time em campo, toda a ação encontra validade para obter vantagem sobre o rival e instaurar a soberania e o poder. ${ }^{24}$

Cabe destacar que a superestimação da violência nos estádios de futebol pela mídia veicula um esporte através do pão e circo. Nesse contexto, cada partida é um espetáculo alimentado por uma violência que proporciona alegria e prazer. O futebol é capaz de provocar mudanças de comportamento nos indivíduos envolvidos pela excitação. ${ }^{31}$

A ira, diferentemente da paixão, é um conjunto de emoções virtuosas de predominância agressiva e de que pouco se tem controle quando transformada ação agressiva em violenta. Essa destrói o bom senso, leva a movimentação das massas pelo calor das discussões e ânimos exaltados e pode explodir a qualquer momento. A violência é perigosa, pois pode levar a crer que é controlável, mas, na verdade, não se tem o controle sobre seu fluxo. ${ }^{32}$

No âmbito dos estádios, a emoção e excitação criadas pelo futebol e no futebol envolvem formas de conflitos que se encontram entrelaçadas, de maneira sutil, em forma de prazer ou de sofrimento e compreendem uma mistura complexa e variável de comportamento racional e irracional. As várias descobertas recentes do instinto de dominação e da agressividade inata ao humano estão precedidas de afirmações filosóficas, que para Kowalski, ${ }^{24}$ partem do pressuposto da paixão perigosa oriunda da ira e da tensão em cada partida. Nesta perspectiva, considera-se que, na raiz da violência, encontra-se a falta de desenvolvimento do senso moral, que o espírito deveria aprimorar pela educação através do exercício dos valores éticos e da amplitude de consciência. Considerando os antecedentes históricos, face às vinculações com os reflexos instintivos do período animal, a paixão é uma ação edificante quando prazerosa, 
entretanto pode declinar a tal ponto de excitar perturbadores à violência coletiva. Não apenas gera aflição quando desencadeada, como também, provoca reações equivalentes em sucessão incontrolável, arrebentando tudo que se lhe opõe tornando o seu percurso destrutivo.

\section{CONCLUSÃO}

A crescente necessidade de arrefecimento das pulsões de violência e agressividade, equacionada pelo processo de pacificação social, a que Elias ${ }^{14,31}$ denominou "processo civilizador", vem sendo imposta pela complexificação e interdependência da vida coletiva. Esse comedimento está sobrecarregado de sansões e procedimentos proibitivos de condutas não mais aceitas no homem da sociedade contemporânea.

Considerando o significado atribuído ao futebol no Brasil e em todo o mundo, permite-se afirmar que os aspectos mais intimamente relacionados às vivências de emoções se desdobraram em situações de violência urbana e coletiva, tanto nas ruas das cidades quanto no interior dos estádios.

Assim, a presença das torcidas nos estádios de futebol no Brasil preenchem importantes funções sociais, que são comumente categorizadas em "funções manifestas, latentes ou agonísticas". 33 Para esses autores, estas funções dizem respeito à supressão das necessidades de atividade física; a compensação do estresse provocado pela rotina de trabalho e a satisfação “dos instintos mais profundos do ser humano, o instinto combativo, que está relacionado à luta pela sobrevivência e ao impulso sexual". Na concepção de Elias e Dunning, ${ }^{31}$ quanto mais civilizada uma sociedade maior é a exigência de espaços especificamente destinados à vivência de emoções.

Os estádios de futebol são espaços destinados a excessos e euforias coletivas. São espaços conclamados a inversão dos comportamentos do mundo cotidiano (rotina de trabalho, trânsito e afazeres domésticos) e colocá-lo 'literalmente' a serviço de realizações subjetivas e coletivas. São lugares de "descontrole-controlado", ainda que tais elementos tenham sido relegados a um segundo plano da cena social por conta da própria modernização da sociedade.

Portanto, o que a sociedade e mais especificamente os dirigentes dos festivais futebolísticos nos estádios não podem perder de vista é que o futebol representa, por vocação, a passagem do divertimento ocasional para uma experiência existencial institucionalmente organizada. 
Uma verdadeira regulamentação dos passatempos. ${ }^{31}$ Essa regulamentação em que deveria se estruturar o futebol poder-se-ia trazer contribuições significativas para se evitar o descontrole das paixões e emoções pelos torcedores nos estádios.

Afirma-se veemente, não se está sugerindo que, por conta disso, a presença do torcedor nos estádios de futebol tenha que perder completamente seu elemento lúdico capaz de satisfazer os desejos de emoção e paixão pelo time em campo.

Se isso acontecer, provavelmente, as partidas de futebol, organizadas na modalidade de campeonatos brasileiros não atrairiam a atenção apaixonada de tantas pessoas.

Ao se considerar o comportamento entre duas torcidas num estádio, não se pode deixar de mencionar que os relacionamentos humanos surgem, inicialmente, de uma sintonia emocional controlada e hedonista - ir ao estádio ver o seu time jogar. Para tal, há a aptidão da empatia que, além de permitir que um indivíduo participe da emoção do outro, torna-o pró-ativo em relação às necessidades do outro. No entanto, a qualidade deste relacionamento dependerá do nível de desenvolvimento de outras aptidões como a consciência de que seu time pode perder e autocontrole quando ele vencer.

Nesta perspectiva, a emocionalidade surge para revelar ao homem que as emoções, outrora consideradas inoportunas em algumas situações, podem ter um valor incalculável nas decisões esportivas quando bem administradas.

Conseqüentemente, quando não controladas por indivíduos e grupos, a aplicação da emoção na dosagem errada, é um estopim que aniquila o fator de sucesso, erradica por completo a possibilidade de manter os estádios como espaços abertos, neutros politicamente e pacíficos, pois, essa emoção descontrolada é uma paixão perigosa. Enfim, o que está se tentando evidenciar é que se está diante de uma situação extrema que precisa ser revista na sociedade brasileira.

\section{REFERÊNCIAS}

${ }^{1}$ CAGIGAL, J. M. Deporte y agresion. Madrid: Alianza, 1990. 
${ }^{2}$ MURAD, M. A violência e o futebol: dos estudos clássicos aos dias de hoje. Rio de Janeiro: Editora FGV, 2007 .

${ }^{3}$ MANDELL, R. Historia cultural del deporte. Espanha: Ediciones Bellaterra, 1986.

${ }^{4}$ BODEI, R. Geometría de las pasiones: miedo, esperanza, felicidad - filosofia y uso político. Fondo de Cultura Económica: México, 1995.

${ }^{5}$ MURPHY, P.; WILLIAMS, J.; DUNNING, E. O futebol no banco dos réus: violência dos espectadores num desporto em mudança. Oeiras: Celta, 1994.

${ }^{6}$ PIMENTA, C. A. M. (2000). Violência entre torcidas organizadas de futebol. Revista São Paulo em Perspectiva, v. 14, n. 2, 2000.

${ }^{7}$ ANDERSON, C.; HUESMANN, L. Human aggression: a social cognitive view. The Sage Handbook of Social Psychology. New York: Sage, 2003. Disponível em: http://www.sageereference.com/hdbk_socpsych/Article_n12.html. Acesso em: 26 abr. 2010.

${ }^{8}$ DUNNING, E. Sport matters: sociological studies of sport, violence and civilization. London: Routledge, 1999.

${ }^{9}$ DUNNING, E. Spectator violence. In: Encyclopedia of crime and punishment. 2002. Disponível em: http://www.sageereference.com/crimepunishment/Article n410.html. Acesso em: 26 abr. 2010.

${ }^{10}$ MARCONI, M. A.; LAKATOS, E. M. (2010). Fundamentos de metodologia cientifica. 7. ed. São Paulo: Atlas, 2010.

${ }^{11}$ GOLEMAN, D. Emocionalidade: a teoria que redefine o que é ser inteligente. 60. ed. Rio de Janeiro: Objetiva, 1995.

${ }^{12}$ STRONGMAN, K. T. A psicologia da emoção. Lisboa: Climepsi Edes, 1998.

${ }^{13}$ ARENDT, A. Sobre a violência. Rio de Janeiro: Relume-Dumará, 1994.

Conexões: revista da Faculdade de Educação Física da UNICAMP, Campinas, v. 9, n. 1, p. 54-66, jan./abr. 2011. ISSN: 1983-9030 
${ }^{14}$ ELIAS, N., DUNNING, E. (1995). Desporte y ócio en el processo de la civilización. México: Fondo de Cultura Econômica, 1995.

${ }^{15}$ ABBAGNANO, N. Dicionário de filosofia. 4. ed. São Paulo: Martins Fontes, 2000.

${ }^{16}$ HUIZINGA, J. Homo ludens: o jogo como elemento da cultura. São Paulo: Perspectiva, 2004.

${ }^{17}$ WEISHEIPEL, J. E. Tomás de Aquino, vida, obras y doctrina. Pamplona: Eunsa, 1994.

${ }^{18}$ AQUINO, T. Sobre o ensino (De Magistro) \& os sete pecados capitais. São Paulo: Martins Fontes, 2001.

${ }^{19}$ DARWIN, C. A expressão das emoções no homem e nos animais. São Paulo: Cia das Letras, $2000^{21}$ BAUDRILLARD, J. A Transparência do mal: ensaio sobre fenômenos extremos. Campinas: Papirus, 1992.

${ }^{20}$ GIULIANOTTI, R. Sociologia do futebol: dimensões históricas e socioculturais do esporte das multidões. São Paulo: Nova Alexandria, 2002.

${ }^{22}$ PAULA, A. R. (2005). Violência das torcidas e racismo no futebol: o que a escola tem com isto? Revista Urutágua, v. 14, n. 7, p. 21-37, 2005.

${ }^{23}$ WILLIAMS, J.; DUNNING, E.; MURPHY, P. Hooligans abroad: the behaviour and control of english fans in continental europe. London: Routledge, 1984.

${ }^{24}$ KOWALSKI, M. Futebol: a esportivização do brasileiro. Viçosa: Ed. da Univ. Fed. de Viçosa, 2009.

${ }^{25}$ MAFFESOLI, M. Os tempos das tribos: o declínio do individualismo nas sociedades de massa. 4. ed. Rio de Janeiro: Forense, 2006. 
${ }^{26}$ SOUZA, E. R.; MINAYO, M. C. S. O impacto da violência social na saúde pública no Brasil. In MINAYO, M. C. S. (Org.). Os muitos brasis: saúde e população na década de 80. São Paulo: Hucitec, 1995. p. 87-116.

${ }^{27}$ DOMENACH, J. M. La violencia y sus causas. Paris: Unesco, Paris, 1981.

${ }^{28}$ ENGELS, F. Teoria da violência. Ática: São Paulo, 1981.

${ }^{29}$ FONSECA, C. Bandidos e mocinhos: antropologia da violência no cotidiano. Revista do IFCH da UFRGS, v. 16, n. 2, p. 67-89, 1993.

${ }^{30}$ FREUD, S. Obras Psicológicas Completas de Sigmund Freud. Rio de Janeiro: Imago, 1980. (Edição Standard Brasileira)

${ }^{31}$ ELIAS, N.; DUNNING, E. A busca da excitação. Lisboa: Difel, 1992.

${ }^{32}$ PEARSON, K. (1988). Deception, Sportsmanship and Ethics. In: MORGAN, W. J.; MEIER, K. V. Philosophic inquiry in sport. Champaign: Human Kinetics, 1988.

${ }^{33}$ ELIAS, N. O processo civilizador: uma história dos costumes. Rio de Janeiro: Zahar, 1993. v. 1 .

${ }^{34}$ ELIAS, N. O processo civilizador: formação do estado e civilização. Rio de Janeiro: Jorge Zahar, 1994. v. 2.

${ }^{35}$ PRONI, M.; LUCENA, R. F. Esporte: história e sociedade. Campinas: Autores Associados, 2002. 